\title{
Stirling Engines for Distributed Low-Cost Solar-Thermal-Electric Power Generation
}

\begin{abstract}
Artin Der Minassians ${ }^{1}$
e-mail: artin.der.minassians@gmail.com
\end{abstract}

\author{
Seth R. Sanders \\ Professor \\ e-mail: sanders@eecs.berkeley.edu \\ Department of Electrical Engineering and \\ Computer Sciences, \\ University of California, Berkeley, \\ Berkeley, CA 94720
}

Due to their high relative cost, solar-electric energy systems have yet to be exploited on a widespread basis. It is believed in the energy community that a technology similar to photovoltaics, but offered at about $\$ 1 / \mathrm{W}$, would lead to widespread deployment at residential and commercial sites. This paper addresses the feasibility study of a low-cost solar-thermal electricity generation technology, suitable for distributed deployment. Specifically, we discuss a system based on nonimaging solar concentrators, integrated with free-piston Stirling engine devices incorporating integrated electric generation. We target concentrator collector operation at moderate temperatures, in the range of $120^{\circ} \mathrm{C}$ to $150^{\circ} \mathrm{C}$. This temperature range is consistent with the use of optical concentrators with low-concentration ratios, wide angles of radiation acceptance which are compatible with no diurnal tracking and no or only a few seasonal adjustments. Therefore, costs and reliability hazards associated with tracking hardware systems are avoided. This paper further outlines the design, fabrication, and test results of a single-phase free-piston Stirling engine prototype. A very low loss resonant displacer piston is designed for the system using a very linear magnetic spring. The power piston, which is not mechanically linked to the displacer piston, forms a mass-spring resonating subsystem with the gas spring, and has a resonant frequency matched to that of the displacer. The design of heat exchangers is discussed, with an emphasis on their low fluid friction losses. Only standard low-cost materials and manufacturing methods are required to realize such a machine. The fabricated engine prototype is successfully tested as an engine, and the experimental results are presented and discussed. Extensive experimentation on individual component subsystems confirms the theoretical models and design considerations. Based on the experimental results and the verified component models, an appropriately dimensioned Stirling engine candidate is discussed. [DOI: 10.1115/1.4003144]

\section{Introduction}

There has been an ongoing effort on low-cost solar-thermalelectric power generation technology in the EECS department at UC Berkeley over the past decade. The proposed energy conversion system is envisioned to convert solar power into electricity in three stages: solar to thermal, thermal to mechanical, and mechanical to electrical. The system is conceived to operate with collector temperatures in the range of $120^{\circ} \mathrm{C}$ to $150^{\circ} \mathrm{C}$, which is consistent with the use of stationary solar thermal collectors employing low-concentration nonimaging reflectors [1-3]. A nontracking system avoids the costs and maintenance issues associated with tracking collectors with high concentration ratios. Thus, a nonimaging solar collector is a very suitable component to serve as the first energy conversion stage of the proposed system. Figure 1 illustrates the schematic diagram of the proposed system.

A Stirling engine is utilized to convert the delivered heat by the solar collector into mechanical power. One potential advantage of the Stirling cycle is the possibility of using air as the working fluid, thus avoiding issues with long-term containment of a working fluid, such as helium, and the associated maintenance requirements. Further, recent success in demonstrating very low differential temperature engines is also compelling [4]. In the system conceived here, the Stirling engine converts moderate temperature heat to electricity by way of integrated electric generation. However, the use of low-temperature heat limits the theoretical maxi-

\footnotetext{
${ }^{1}$ Corresponding author.

Contributed by the Solar Energy Division of ASME for publication in the JouRNAL OF Solar EnERgy EngineERING. Manuscript received September 11, 2007; final manuscript received August 14, 2010; published online February 14, 2011. Assoc.
} Editor: Manuel Romero Alvarez. mum thermodynamic efficiency achievable by the heat engine, which limits the overall system efficiency. This disadvantage, however, can be compensated by lower costs in materials and in reduced maintenance. The cost effectiveness of solar-electric technologies should be judged by output power per dollar rather than by efficiency or other technical merits [5]. This view reflects the observation that there are vast, untapped siting opportunities in both urban and rural regions of the world. The proposed solarthermal-electric system is designed for fabrication out of low-cost commodity materials. A collector is built of glass, copper, aluminum, stainless steel, selective coating, and insulation, while engines and generators are primarily steel, aluminum, copper, and plastics. In high-volume manufacturing, the cost of the proposed system will be determined by the weight of its bulk materials. This study of solar-thermal-electric systems involves engineering a cost-effective balance between system efficiency and materials cost. The rejected heat of the Stirling engine may potentially be used to provide hot water and space heating. Furthermore, a key distinguishing feature of this solar thermal technology is that a thermal storage unit on the hot side of the engine enables ondemand electricity generation.

In the sequel, first the economic feasibility of the proposed power generation technology is presented. Considering that solarthermal technology is mature, this paper focuses on the design, fabrication, and experimental verification of a gamma-type freepiston Stirling engine prototype that operates at moderate temperature differentials. This low-power prototype is designed and fabricated as a test rig to provide a clear understanding of the Stirling cycle operation at moderate temperature differentials, to identify design strategies for the key components and the major causes of irreversibility, and to verify corresponding theoretical models. The designs of a very low loss resonant displacer piston, 


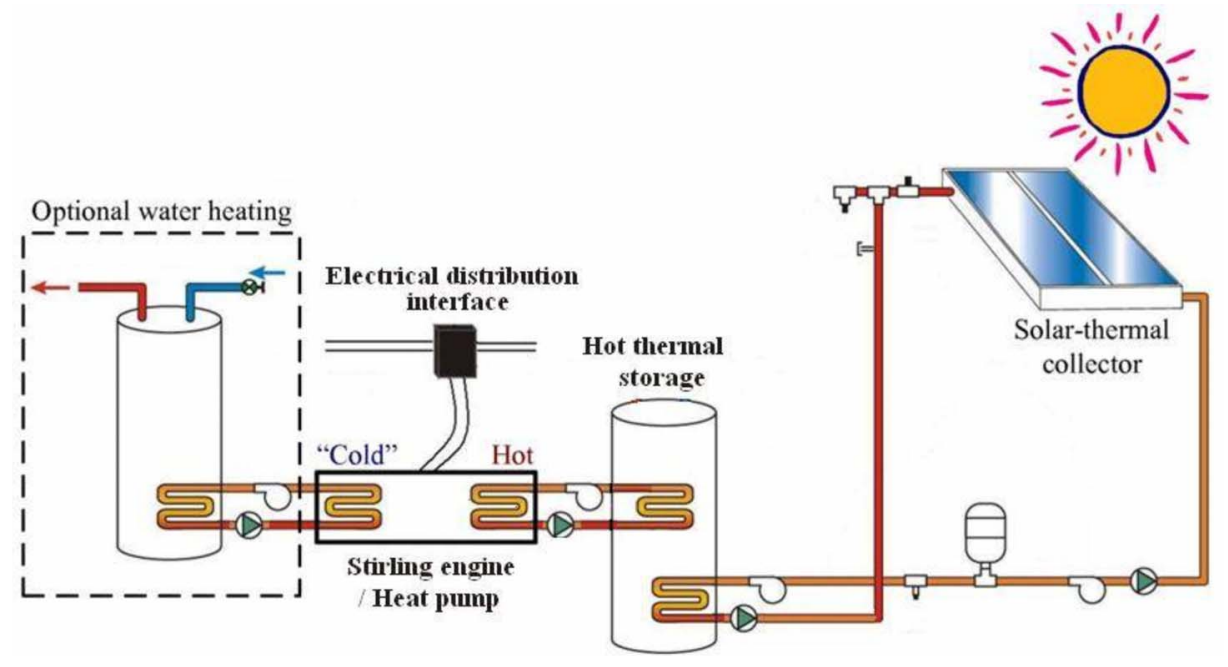

Fig. 1 Schematic diagram of the solar-thermal-electric power generation system

of the heat exchangers, and of the power piston, as key components, are elaborated. The description of the overall engine design is delineated through simulation results. The designs of the displacer piston and the heat exchangers are presented and compared with measurements in detail. The assessment of the fabricated prototype engine successfully supports the models and assumptions. The experimental results and model verification lead to a higher-power Stirling engine design that is outlined in Sec. 6.

\section{System Efficiency and Cost Analysis}

For the conceived system, the efficiencies of a representative solar collector (Schott ETC 16 [3]), the Stirling engine, and the overall system are plotted as a function of temperature in Fig. 2. To minimize the cost per watt of output electricity, it is desirable to operate a system of a given cost at a temperature corresponding to peak system efficiency. This temperature is a function of collector properties as well as ambient temperature and intensity of sunlight. The heat engine can be designed to regulate its loading to maintain optimum collector temperature and system efficiency. Figure 2 shows that the system efficiency is rather flat over a range of temperatures near the extremum.

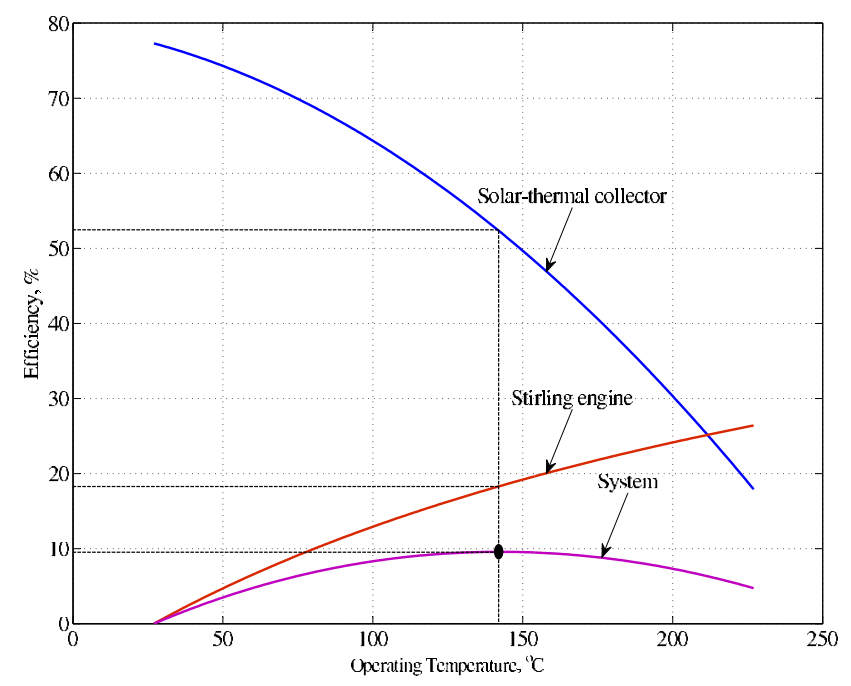

Fig. 2 Efficiency of solar collector (Schott ETC 16 [3]), Stirling engine, and system as a function of temperature for a representative system. The dot indicates the point of optimal system efficiency.
For the data in Fig. 2, an operating temperature of $142^{\circ} \mathrm{C}$ permits a maximum thermodynamic (Carnot) efficiency of $27.7 \%$, assuming that the sink temperature is $27^{\circ} \mathrm{C}$. We might reasonably expect the Stirling engine and generator to achieve a thermalelectric efficiency of about $18.3 \%$, roughly $66 \%$ of the Carnot efficiency, while the collector operates at a thermal efficiency of about $52.3 \%$. Thus, the estimated overall efficiency of the system would be about $9.6 \%$.

The system cost per watt of the peak electricity output is an important figure of merit in judging the cost effectiveness of an investment in an electrical generation system. Since investors prefer a short period after which the revenue from energy sold offsets the initial investment, the output power of the system should be maximized for a fixed capital cost [5]. Photovoltaic (PV) modules currently retail for as low as $\$ 3.29 / \mathrm{W}$ of peak output electrical power [6]. Assuming that the Stirling engine cost is negligible, for a peak insolation of $1000 \mathrm{~W} / \mathrm{m}^{2}$ and an overall system efficiency of $9.6 \%$, the collectors for our system must retail for less than $\$ 315 / \mathrm{m}^{2}$ to match the present day price of PV technology. A 2003 market survey of stationary collectors for solar heat revealed that several models retailed for less than $\$ 200 / \mathrm{m}^{2}$ in quantities of $500 \mathrm{~m}^{2}$, independent of performance [5]. Furthermore, the manufacturing cost of evacuated tube collectors is less than $\$ 3$ per tube [7]. Considering that each tube provides about $870 \mathrm{~cm}^{2}$ input aperture area, the estimated cost of a representative solar-thermal collector is less than $\$ 0.50 / \mathrm{W}[8]$.

The cost of the Stirling engine may be estimated by calculating the mass of materials used in a prototype design [8-12]. Based on fabricated prototypes, the estimated cost for a $2-3 \mathrm{~kW}$ engine can easily be $\$ 0.30 / \mathrm{W}$ or even less, considering economies of scale. Simple design changes can reduce the amount of copper used in the system. The metal content of the engine can be reduced by replacing many metallic parts with plastics, which will further reduce the contribution of the engine to the overall system cost. Further, power density can be increased, resulting in additional cost reduction. Thus, an argument can be made for a complete system cost (collector and engine) at around $\$ 0.80 / \mathrm{W}$.

Nonimaging compound parabolic concentrator (CPC) collectors have the potential to provide temperatures of about $220^{\circ} \mathrm{C}$ at $50 \%$ thermal efficiency [7]. This operating temperature can raise the overall system efficiency to above $14 \%$. The modular nature of such collectors could drastically reduce the installation costs, which is a serious hurdle for the PV industry. In addition, by sacrificing a little bit of electrical efficiency, the Stirling engine can reject heat at $50-60^{\circ} \mathrm{C}$ and can produce hot water without a large capital cost for residential applications. 


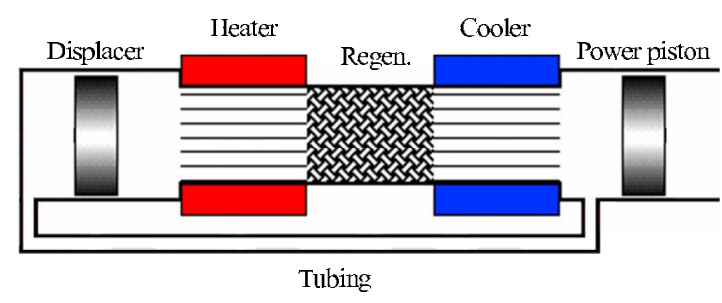

Fig. 3 Simplified schematic diagram of the conceived Stirling engine

\section{Stirling Engine Design}

Figure 3 depicts the simplified schematic diagram of the engine representing the pistons and the heat exchanger configuration of the system. As mentioned above, this low-power prototype is designed as a test rig to identify the key components and the major causes of irreversibility and to verify corresponding theoretical models. The gas circuit of the displacer subsystem is closed by means of tubing in order to provide a closed engine chamber. Both the displacer and the power piston have identical dimensions. In single-phase operation, the power piston interacts with ambient pressure on one side and with engine chamber pressure on the other. To facilitate tight clearance sealing, and thus minimal enthalpy loss, the power piston is located on the cold side of the engine.

The engine design parameters are tabulated in Table 1. The displacer piston shuttles the working fluid between expansion and compression spaces at an operating frequency of $3 \mathrm{~Hz}$. Furthermore, the mass of the power piston has been chosen such that it resonates with the gas spring approximately at the operating frequency. When loaded via its integrated alternator, the power piston behaves as a resonating system with a low quality factor (or high dissipation). Thus, it does not require high precision in tuning its resonant frequency. A dynamical simulation has been car-

Table 1 Engine thermodynamic design parameters. Volume multipliers indicate the porosity of each section.

\begin{tabular}{lc}
\hline \hline Operating temperatures & $T_{h}^{\text {ave }}: 175^{\circ} \mathrm{C}$ \\
& $T_{k}^{\text {ave }}: 25^{\circ} \mathrm{C}$ \\
Indicated powers & Schmidt analysis \\
Input: $75.1 \mathrm{~W}$ \\
Output: $25.2 \mathrm{~W}$ \\
Efficiency: $33.6 \%$ \\
\\
Adiabatic model \\
Input: $253.6 \mathrm{~W}$ \\
Output: $23.8 \mathrm{~W}$ \\
Efficiency: $9.4 \%$
\end{tabular}

Heater

Housing volume: $210 \mathrm{~cm}^{3} \times 27.5 \%$ Hydraulic diameter: $0.6 \mathrm{~mm}$ Wetted area: $0.35 \mathrm{~m}^{2}$

Cooler

Housing volume: $210 \mathrm{~cm}^{3} \times 23 \%$ Hydraulic diameter: $0.5 \mathrm{~mm}$ Wetted area: $0.37 \mathrm{~m}^{2}$

Regenerator

Housing volume: $260 \mathrm{~cm}^{3} \times 63.4 \%$ Hydraulic diameter: $0.2 \mathrm{~mm}$ Wetted area: $1.9 \mathrm{~m}^{2}$

\begin{tabular}{cc} 
Pistons & $\begin{array}{c}\text { Diameter: } 10 \mathrm{~cm} \\
\text { Stroke: } 15 \mathrm{~cm}\end{array}$ \\
Tubing & Volume: $500 \mathrm{~cm}^{3}$ \\
& Hydraulic diameter: $19 \mathrm{~mm}$ \\
\hline
\end{tabular}

ried out using the Stirling engine adiabatic model [13]. Figure 4 shows the simulation results in terms of temperature and volume variations of the compression and expansion spaces as well as pressure variation of the engine chamber and the $p-V$ diagram of the Stirling cycle. Based on this simulation, with a $150^{\circ} \mathrm{C}$ difference between hot and cold side average temperatures, the indicated output power of the engine is about $26.9 \mathrm{~W}$ at a $9.4 \%$ thermal efficiency. We note that this engine is conceived to operate with ambient air.

In the sequel, the designs of the displacer piston, the heat exchanger, and the power piston subsystems are discussed in detail, with an emphasis on the loss contribution of each element.

\section{Design}

4.1 Displacer Subsystem. The displacer is designed as a reciprocating piston that moves along a shaft with a stroke of $15 \mathrm{~cm}$ at the design frequency of operation (i.e., $3 \mathrm{~Hz}$ ). It is in contact with hot gas (as high as $200^{\circ} \mathrm{C}$ ) at one end and with cold gas (about $30^{\circ} \mathrm{C}$ ) at the other, as shown in Fig. 5. Thus, in addition to enduring the higher temperature, the displacer body material should minimize the heat leakage path between hot and cold spaces. In order to fulfill both requirements, among hightemperature plastics, Teflon (polytetrafluoroethylene) and PEEK (polyetheretherketone) are good candidates. Both materials endure temperatures of up to $250^{\circ} \mathrm{C}$ and have a low thermal conductivity $(0.25 \mathrm{~W} / \mathrm{m} \mathrm{K})$. The heat leakage through the displacer piston is expected to be about $2 \mathrm{~W}$ if fabricated from either of these two materials. For its superior machinability properties and higher tensile strength, PEEK is selected for the fabrication of the displacer piston prototype.

The displacer piston is designed to resonate with a linear spring. Considering the limited life of mechanical springs and other challenges presented by these components, a design is carried out with an embedded linear magnetic spring to obviate mechanical failures and ensure long operation life [8]. Figure 6 depicts the fabricated displacer piston and the magnetic spring assembly. The details of the design, fabrication, and experimental results of the magnetic spring assembly and the linear alternator were documented in Refs. $[8,11]$ by the authors and will not be repeated in this paper.

An embedded linear motion ball bearing enables a low friction and smooth piston motion. However, exposure of steel bearing balls to the surrounding magnetic fields impedes rolling. Hence, steel balls are replaced by nonmagnetic ceramic (silicon nitride) balls. An average coefficient of friction for a linear motion ball bearing is between 0.002 and 0.004 . This means an average power dissipation of $0.05-0.1 \mathrm{~W}$ for the nominal horizontal operating conditions of the displacer with a mass of about $2.9 \mathrm{~kg}$.

The displacer cylinder has been fabricated out of PEEK as well. In addition to eliminating any potential eddy loss and allowing for minimal thermal leakage between hot and cold spaces, it is a good match with the piston in terms of thermal expansion considerations. As a result of the small pressure difference between the two ends of the displacer piston, which is due to a small fluid flow pressure drop through heat exchangers and tubing, clearance sealing is an appropriate way of separating the hot and cold air that are in contact with either end of the displacer piston. At a relatively large clearance of $0.25 \mathrm{~mm}$ between the displacer piston and its cylinder, the average enthalpy loss is estimated to be less than $4 \mathrm{~W}$ for a nominal temperature differential of $150^{\circ} \mathrm{C}$ across the displacer piston [13]. This is negligible compared with $300 \mathrm{~W}$ of required engine input heat. The enthalpy loss may be further reduced by considering a tighter clearance if necessary.

4.2 Heat Exchangers. Heater and cooler geometry, in this design, is based on a fin-tube structure that is fabricated by pressfitting tubes through stacks of etched metal fins (Fig. 7). With a hydraulic diameter of about $0.5 \mathrm{~mm}$, the design is optimized for lower frequencies with pumping powers in the range of $0.2-0.8 \mathrm{~W}$ 


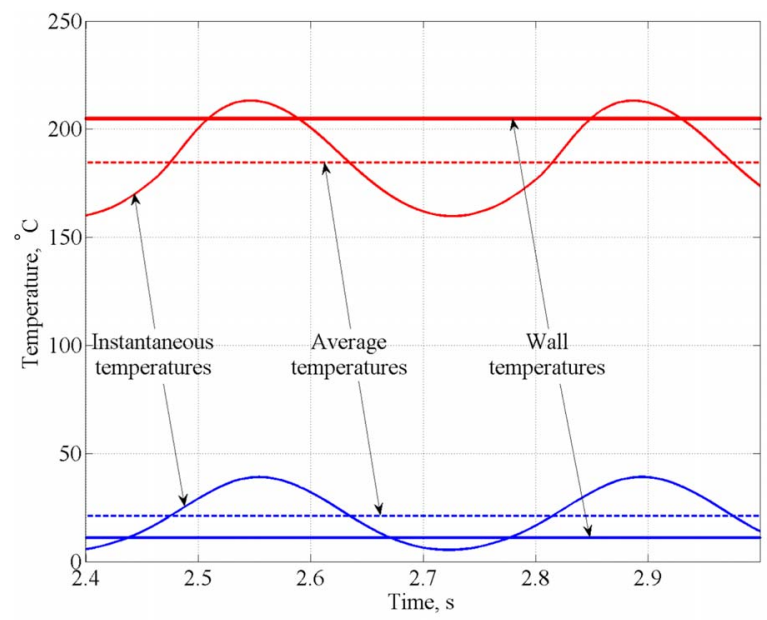

(a)

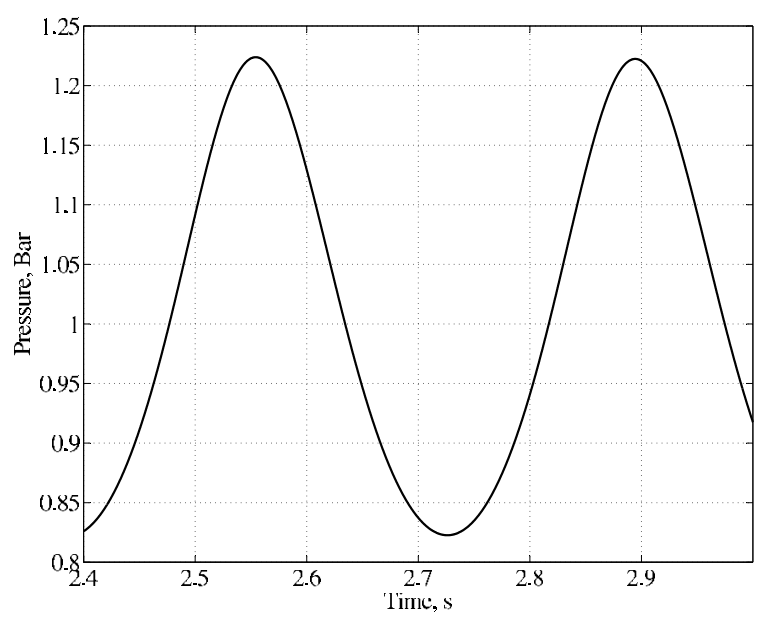

(c)

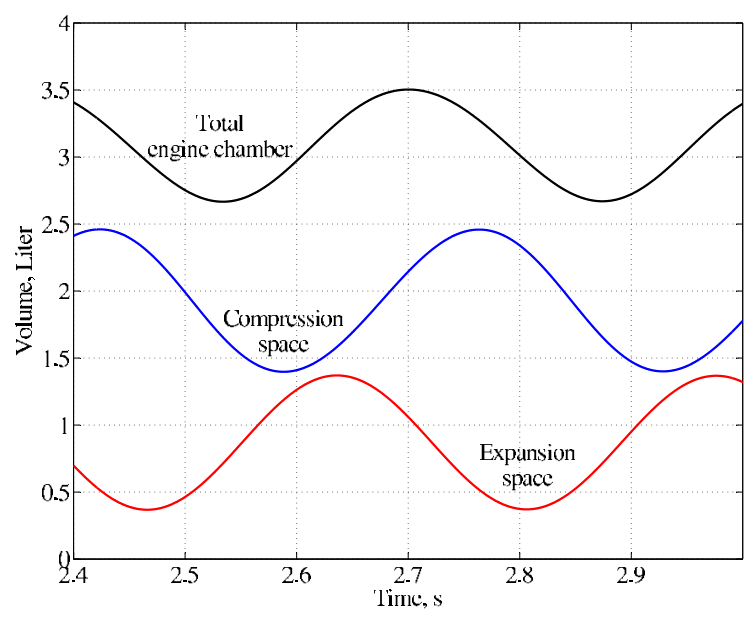

(b)

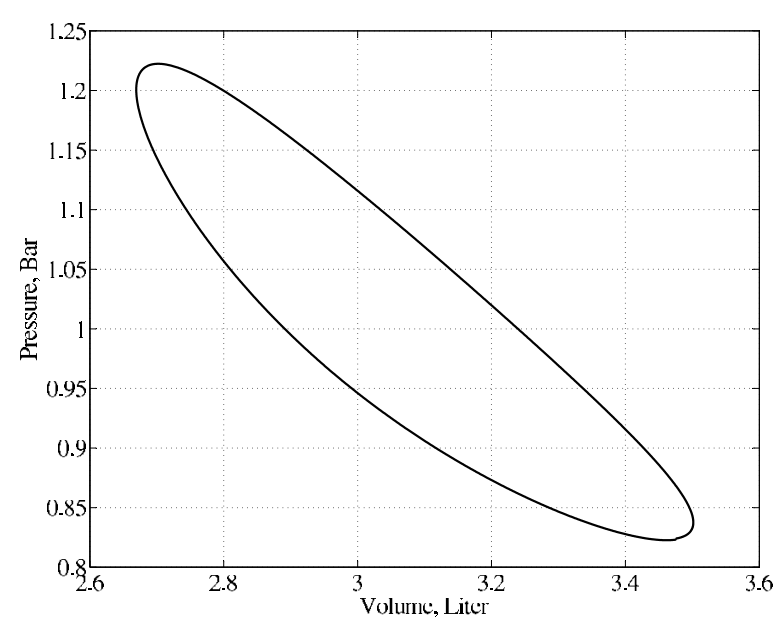

(d)

Fig. 4 Simulation results of the single-phase free-piston Stirling engine thermodynamic behavior. (a) Wall, instantaneous, and average temperatures on hot and cold sides. (b) Expansion space, compression space, and total engine chamber volume variations. (c) Pressure variation. (d) $p-V$ loop of the thermodynamic cycle.

for the heater and cooler combined and a temperature drop of $2-3^{\circ} \mathrm{C}$ for each at a nominal input thermal power of about 300 $\mathrm{W}$. The regenerator is a stack of woven wire screens with a circular cross-section wire. With a hydraulic diameter of about $0.2 \mathrm{~mm}$, the design requires a pumping power of about $0.8-1 \mathrm{~W}$ for the regenerator. The tubing and fittings are analyzed analogously to the heater and cooler. The corresponding fluid flow dissipation is evaluated using the mean cross-sectional velocity of the fluid and correlations outlined in Refs. $[14,15]$. Consequently, these losses contribute an additional $0.5-2 \mathrm{~W}$ to the total flow friction dissipation. The total displacer power loss is estimated to be in the range of $2.05-5.4 \mathrm{~W}$.

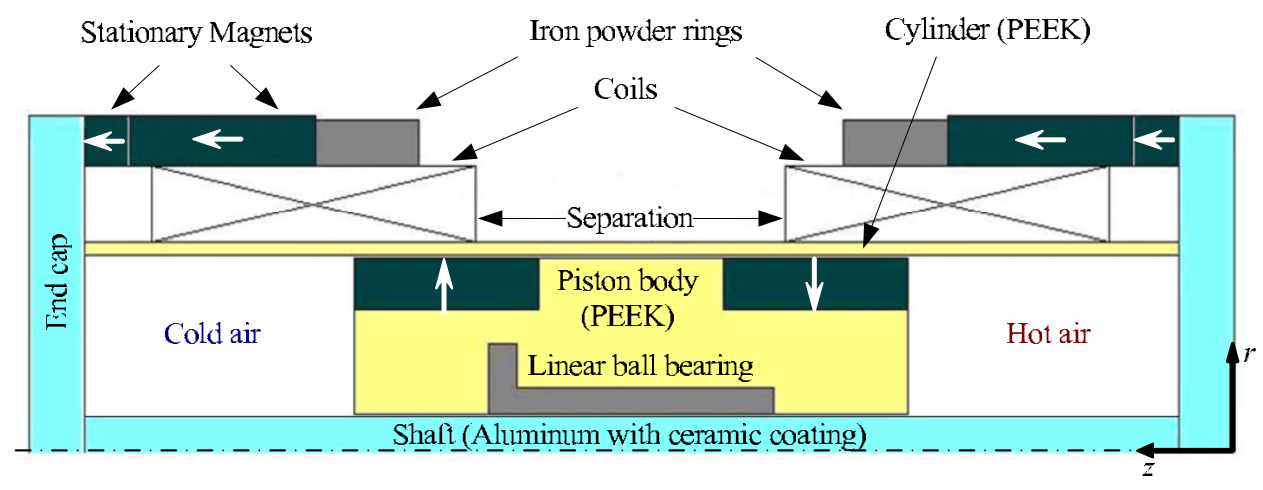

Fig. 5 Schematic diagram of the displacer piston design 


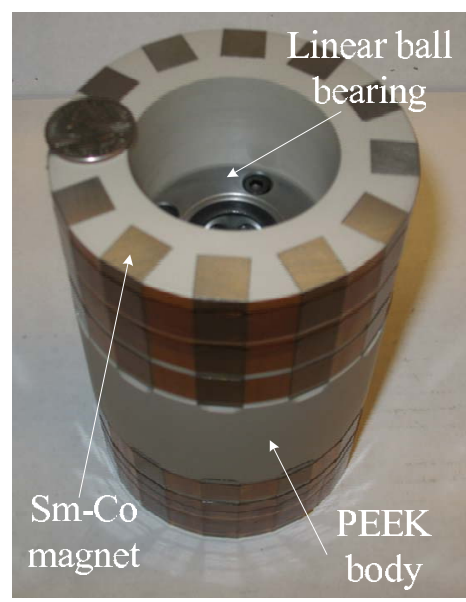

(a)

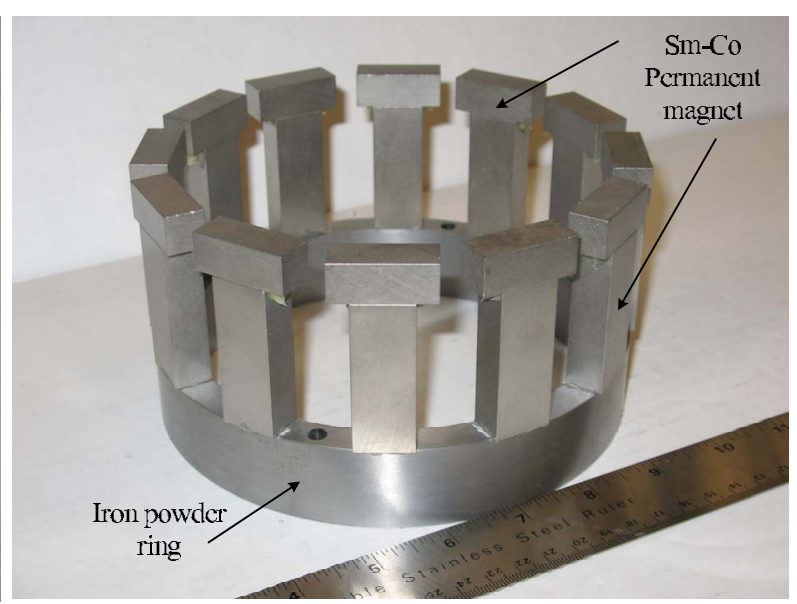

(b)

Fig. 6 (a) Fabricated displacer piston with embedded linear motion ball bearing and permanent magnet arrays. (b) Stationary magnetic array that provides the linear spring function for the displacer. Compare with Fig. 5.

4.3 Power Piston. Since this engine is designed to have the potential of being expanded into a multiphase system, the power piston dimensions (diameter, length, and stroke) are made identical to those of the displacer dimensions. To make such an arrangement, one can easily remove the tubing and convert this system into an alpha-type Stirling engine, which is the most convenient arrangement for a multiphase Stirling engine system [8,10,12].

In this design, the power piston is located on the cold side of the engine. This eliminates any heat leakage in the form of thermal conduction through the piston body and facilitates tighter clearance sealing that is crucial in this case as the pressure difference across the power piston may achieve 0.2 bar, as seen in Fig. 4. Like the displacer, the power piston slides along a shaft that passes through a linear motion ball bearing with nonmagnetic balls that is embedded in the piston. Due to the pressure differential across the power piston, the working fluid will leak in and out through the clearance seal. Calculations predict no more than $1 \mathrm{~W}$ enthalpy loss through the wall clearance.

The power piston is the moving component of a magnetic circuit, similar to the displacer, which converts the output power of the thermodynamic cycle into electricity. The power piston is fabricated out of low-carbon steel with strong $\mathrm{Nd}-\mathrm{Fe}-\mathrm{B}$ permanent magnets installed on one end (Fig. 8). With a mass of $6.4 \mathrm{~kg}$, the power piston resonates with the gas spring at the designated operating frequency. Since the power piston delivers power to the load, it forms a heavily damped resonator as the load acts as the

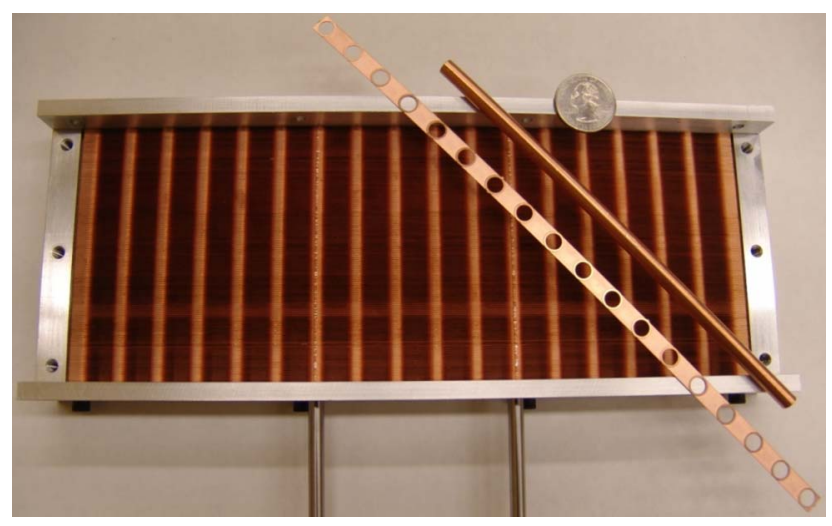

Fig. 7 Fabricated heat exchanger shown with the etched fins and copper tube inserts loss component of the resonating power piston. Therefore, a slight deviation of the power piston gas spring resonant frequency does not hinder the operation of the engine.

The linear motion ball bearing surface friction and eddy loss in the power piston body are the dissipation sources associated with this component. To estimate the loss, we rely on the friction factor that is experimentally obtained for the displacer ball bearing (Sec. 5.1 ). The power piston has a mass of about $6.4 \mathrm{~kg}$, and, hence, the corresponding friction loss at full excursion is estimated to be about $1.25 \mathrm{~W}$. Eddy losses are due to the variable magnetic field that is generated by the load current flowing through the coils. There is no precise estimation for eddy losses at this stage, but they are proven to be very small due to the relatively small load currents. If eddy currents were significant, the piston would have to be manufactured from a material with low electrical conductivity.

\section{Experimental Assessment}

5.1 Displacer Piston. The only anticipated sources of dissipation in the displacer piston are the friction between the linear motion ball bearing and the shaft, and minor eddy losses in the permanent magnets and the iron powder rings. A ring-down test, among others, is an appropriate way of estimating important parameters, such as the natural frequency, quality factor, and damp-

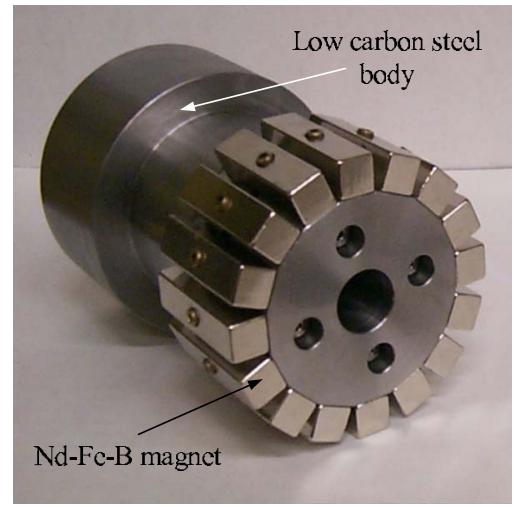

Fig. 8 Fabricated power piston shown with the low-carbon steel body and $\mathrm{Nd}-\mathrm{Fe}-\mathrm{B}$ permanent magnets attached to one end 


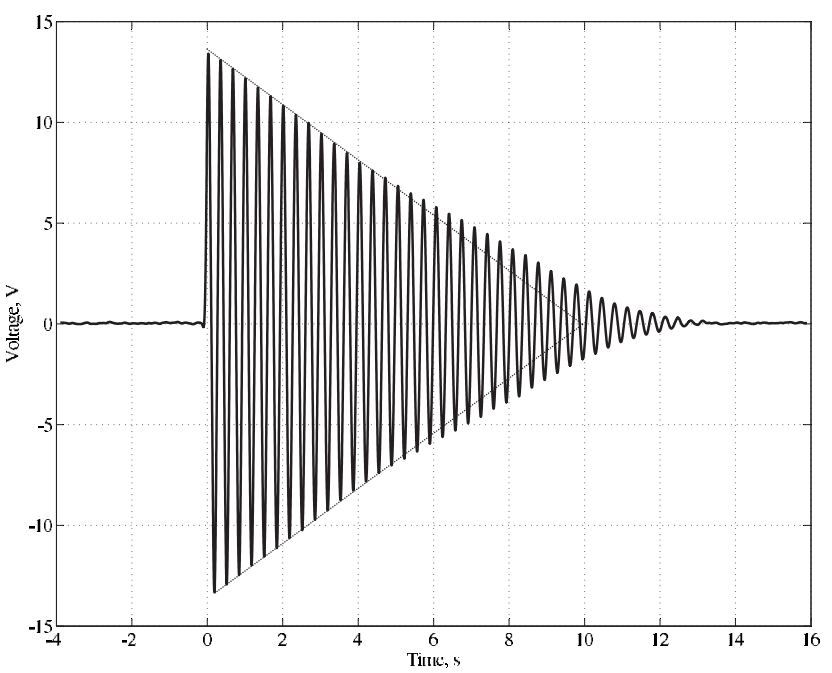

Fig. 9 Ring-down characteristic of the displacer piston

ing factor of this system [8].

Figure 9 shows the ring-down characteristic of the displacer piston by displaying an open circuit actuator winding voltage. The very first peak corresponds to the maximum velocity of the piston (about $1.4 \mathrm{~m} / \mathrm{s}$ ). This test successfully confirms the expected $3 \mathrm{~Hz}$ resonant frequency and low-power dissipation of the system. The behavior of this system is to be analyzed at the largest amplitudes as these are representative of the actual operating conditions. The ring-down envelope for larger amplitudes is clearly a straight line that signifies dry friction as the main source of loss. The estimated attenuation rate of the ring-down characteristic is about $0.14(\mathrm{~m} /$ $\mathrm{s}) / \mathrm{s}$, which corresponds to a friction force of $0.6 \mathrm{~N}$ and a power dissipation of about $0.5 \mathrm{~W}$. To reduce friction, the engine could be aligned with its piston axis vertical. In this case, however, the displacer weight would force the resting position of the piston away from the center of the shaft, reducing the stroke.

In order to verify the estimated power dissipation of the displacer piston, the energy-balance approach is implemented [8]. In this approach, the displacer is run as an actuator and is connected to an ac power supply with the nominal operating frequency of 3 $\mathrm{Hz}$. The mechanical dissipation is calculated as the difference between the measured input power and the copper loss in the windings. In this case, the measured input power and copper loss are $1.75 \mathrm{~W}$ and $0.99 \mathrm{~W}$, respectively. Consequently, it is inferred that $0.76 \mathrm{~W}$ supplies the flow losses driven by the displacer piston, in approximate agreement with the ring-down test.

5.2 Heat Exchangers. Both ring-down and energy-balance tests are appropriate methods to assess the fluid flow friction losses through the heat exchangers and the tubing. This ring-down test yields an estimated power dissipation of $3.2 \mathrm{~W}$ at the nominal operating conditions. The energy-balance method indicates about $3.1 \mathrm{~W}$ of dissipated power for the same conditions.

Table 2 summarizes the estimated losses of the displacer, heat exchangers, and tubing and compares them with the design calcu-

Table 2 Comparison of the calculated component dissipations with the measurement-based estimations

\begin{tabular}{lccc}
\hline \hline Component & $\begin{array}{c}\text { Calculated } \\
(\mathrm{W})\end{array}$ & $\begin{array}{c}\text { Ring-down } \\
(\mathrm{W})\end{array}$ & $\begin{array}{c}\text { Energy-balance } \\
(\mathrm{W})\end{array}$ \\
\hline Piston only & $0.05-0.1$ & 0.5 & 0.76 \\
Heat exchangers & $1.5-3.3$ & 1.1 & 0.49 \\
Pipes and fittings & $0.5-2$ & 1.6 & 1.85 \\
Total & $2.05-5.4$ & 3.2 & 3.1 \\
\hline \hline
\end{tabular}

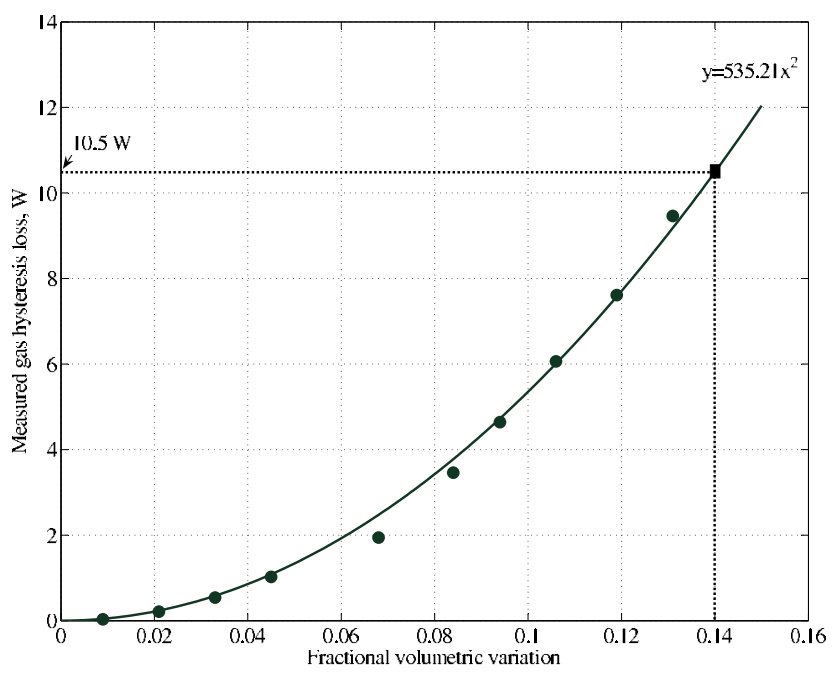

Fig. 10 Gas hysteresis loss characteristic of the fabricated Stirling engine prototype

lations. There is a strong agreement between calculations and estimated values for the fluid flow friction losses, which validates the adopted experimental methodologies and design calculations. The heat exchanger designs are conservative, as expected.

5.3 Power Piston. A ring-down test for the power piston while connected to the engine chamber confirms that the power piston resonates with the gas spring at a frequency of about 2.94 $\mathrm{Hz}$ [8]. A ring-down test in which the power piston is separated from the rest of the engine enables an estimation of the frictional losses. For this test, the ring-down oscillation frequency is low (about $0.8 \mathrm{~Hz}$ ), and more uncertainties may prevail in the estimation. The frictional loss for the power piston is estimated to be 2.8 $\mathrm{W}$ in this test.

Gas hysteresis loss can be a significant source of dissipation for free-piston Stirling engines. In order to characterize the gas hysteresis loss for the fabricated prototype, a compression test is performed by actuating the power piston at its operating frequency. The actuation voltage is varied to achieve various piston strokes and, hence, compression ratios or fractional volumetric variations (FVVs). At each operating point, using the energy-balance approach, one can estimate the power that is dissipated as gas hysteresis loss. Furthermore, the gas hysteresis loss can be estimated by calculating the area enclosed by the measured $p-V$ loop at each operating point as well. The latter approach, adopted in Ref. [8], includes the power piston seal leakage in the estimated value, which is expected not to exceed $1 \mathrm{~W}$ due to the tight clearance. Figure 10 depicts the experimental results of the compression test for the fabricated Stirling engine prototype. As expected from the theoretical model of the gas hysteresis phenomenon, a quadratic function fits the measured data well. As long as the distance of the heat exchanger passages to the outside world is much larger than the thermal skin depth at the operating frequency, the heat exchanger wetted area does not contribute to the gas spring hysteresis dissipation. Therefore, the main contributions to the gas spring hysteresis dissipation come from the open spaces, such as the piston faces and cylinder areas. For the fabricated prototype, the total engine chamber surface area is $0.45 \mathrm{~m}^{2}$. However, the measured gas hysteresis dissipation data suggest a wetted area of about $0.78 \mathrm{~m}^{2}$. The measured characteristic is used in Sec. 5.4 to estimate the gas hysteresis loss at the engine operating point.

5.4 Thermodynamic Cycle. Figure 11 depicts the assembled Stirling engine test rig. In the conceived realization of Fig. 1, the heat transfer fluid would flow through the heater tubes and would transfer the heat from the solar collector to the Stirling engine. However, to avoid complexities of working with very hot fluid 


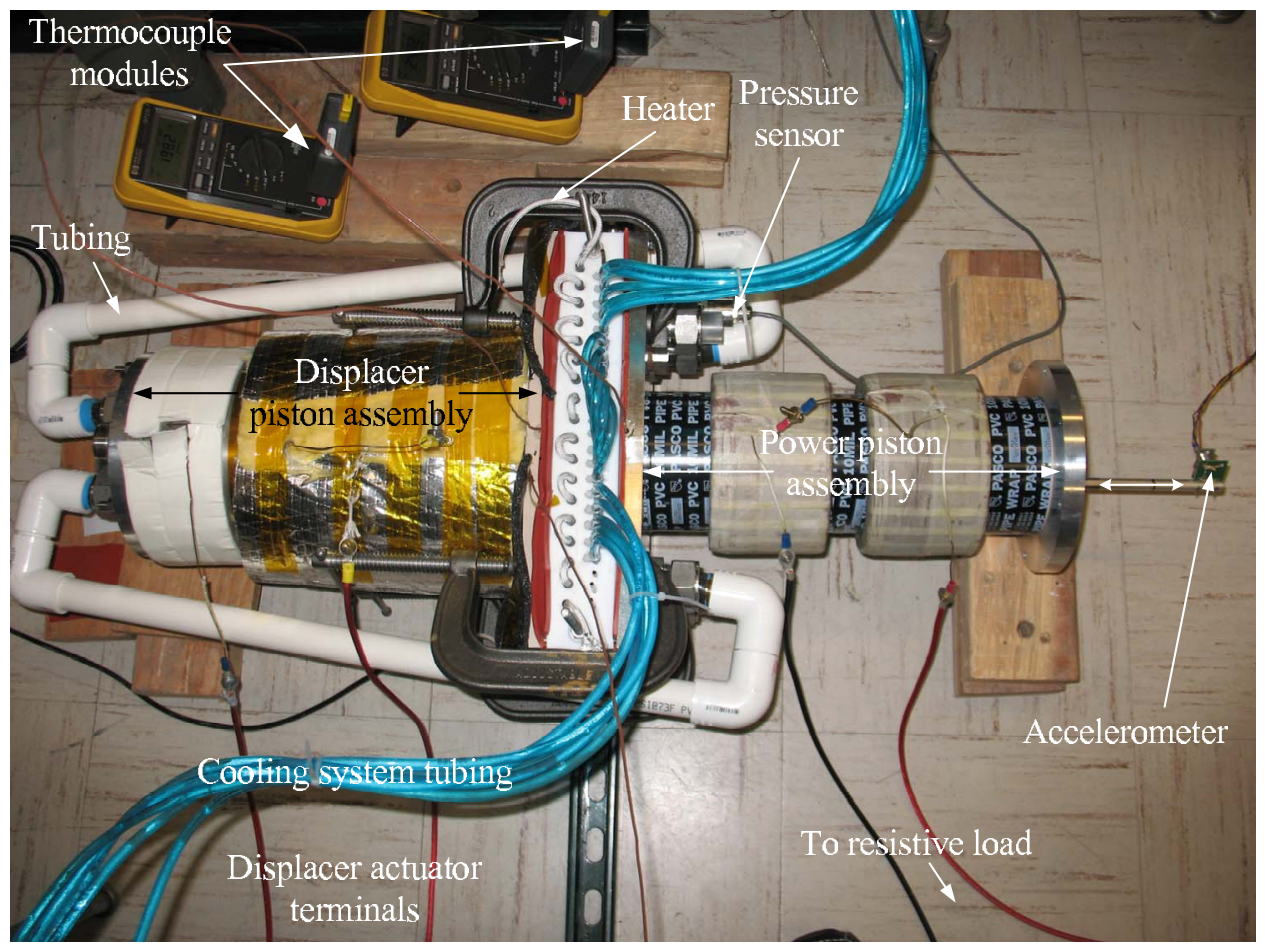

Fig. 11 The Stirling engine experimental setup

(about $200^{\circ} \mathrm{C}$ ) in this experimental prototype, the heater is heated by a voltage-controlled electric heating element that passes through all the heater tubes. By varying the supply voltage of the heating element, one can adjust the input heat and hot side temperature. The voltage and current measurements on the supply are used to calculate the thermal power of the electric heating element. The engine is designed to operate at ambient temperature $\left(27^{\circ} \mathrm{C}\right)$ on the cold side. If ambient air were to circulate through the cooler tubes as the coolant, due to the limited wetted area provided by the tubes, its flow rate would be extremely high to provide a small temperature difference between the coolant and the copper tubes. Therefore, water is chosen as the coolant. Due to its larger specific heat and density, even at low flow rates, water can absorb a significant amount of heat from the cooler at much smaller temperature differences. The inlet and outlet temperatures of the coolant, together with its flow rate, are utilized to estimate the absorbed heat by the cooler.

The displacer is driven by an inverter with adjustable frequency and amplitude. In order to minimize the required driving power, the displacer is driven at its resonant frequency. The voltage amplitude, on the other hand, is adjusted to drive the displacer at its full stroke.

The chamber pressure and power piston acceleration are monitored by appropriate sensing devices. By processing the acceleration data, one can obtain the power piston velocity and displacement signals. Displacement data will yield volume variation as all the dimensions are exactly known from the design. Combining the pressure and volume signals, the $p$ - $V$ diagram of the thermodynamic cycle is obtained, which then characterizes the produced work.

The electric output of the power piston generator is connected to a resistive load. The voltage and current of the load are monitored as well. Therefore, the energy-balance approach may be implemented here to assess the generated power.

Figures 12 and 13 show the measured pressure and volume variations as well as the $p-V$ characteristic of the engine, while the thermocouples measure the working fluid temperatures of $184^{\circ} \mathrm{C}$ and $22^{\circ} \mathrm{C}$ in the vicinity of the heater and cooler, respectively, inside the engine chamber. The displacer piston operates at its full stroke, while the power piston stroke is about $11.7 \mathrm{~cm}$. The thermodynamic cycle output work based on the measured $p$ - $V$ characteristic is $15.9 \mathrm{~W}$. Electrical measurements further confirm that about $9.3 \mathrm{~W}$ is delivered to the resistive load and $5.2 \mathrm{~W}$ is dissipated in the power piston coils. Therefore, one can conclude that about $1.4 \mathrm{~W}$ is dissipated as the power piston frictional and eddy losses. A comparison of the measured data with simulation results (Fig. 4) indicates a good match for the pressure and volume amplitude variations.

As the power piston oscillates, the engine volume varies as a function of the power piston position. FVV is defined as

$$
\mathrm{FVV}=\frac{V_{\max }}{V_{o}}-1
$$

where $V_{\max }$ indicates the maximum volume of the chamber and corresponds to the outmost position of the power piston and $V_{o}$ is the mean value of the volume variation, which corresponds to the resting position of the power piston. The FVV for the above operating conditions is about 0.14 . The gas hysteresis characteristic of the engine (Fig. 10) suggests that $10.5 \mathrm{~W}$ of the output $p V$ work is spent on the gas hysteresis loss. In addition, a small portion of the indicated output power is dissipated as enthalpy loss through the power piston clearance seal as well, which, as mentioned above, is included in the gas hysteresis characteristic.

Note that the thermocouples in the experimental setup are located very close to the heat exchangers, and they measure the working fluid temperature as it exits (or enters) the heat exchangers. Due to the heat leakage in the system, especially through the thin cylinder walls, the measured temperatures are probably higher than the actual average fluid temperatures that govern the thermodynamic cycle. This results in a higher output power prediction based on both isothermal and adiabatic models [13]. Therefore, it is concluded that the remaining $0.5 \mathrm{~W}$ of the dissipated power must be in the form of enthalpy loss through the expansion space walls. 


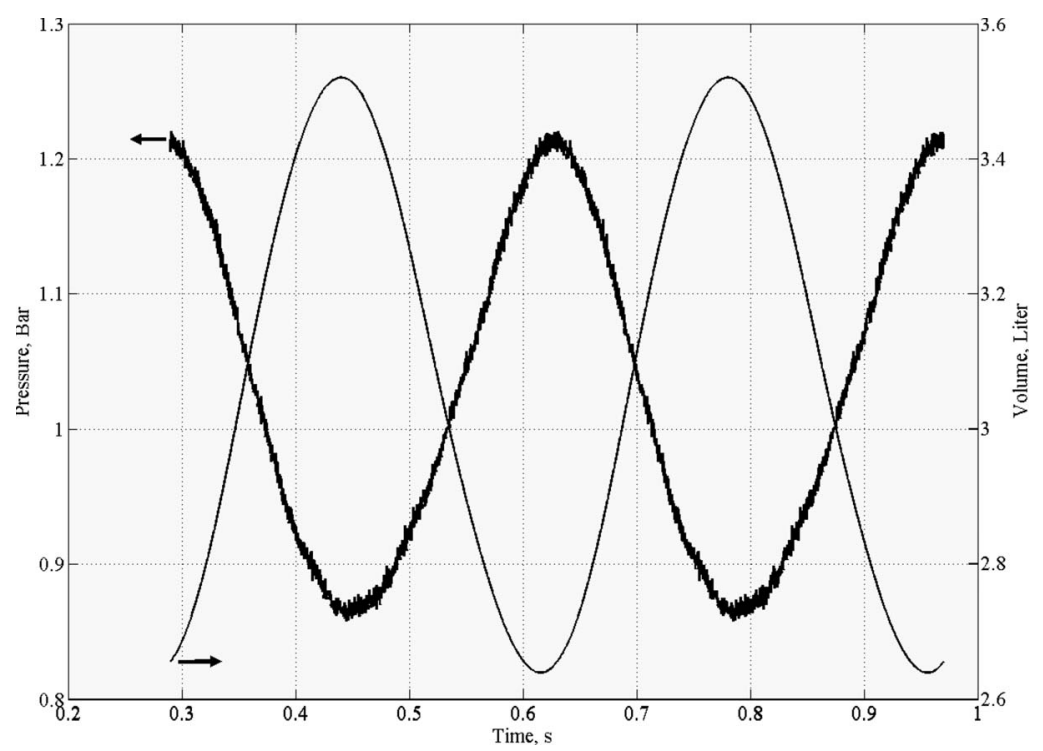

Fig. 12 Measured engine pressure and volume variations. Compare with Fig. 4.

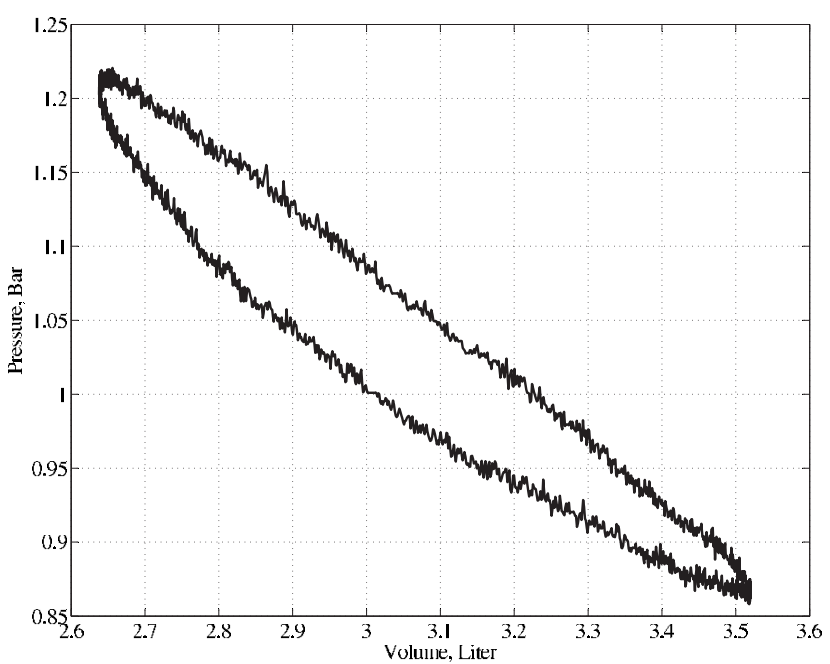

Fig. 13 Measured $p-V$ diagram of the engine

Table 3 Power balance for the fabricated prototype at the operating point discussed in this paper.

\begin{tabular}{lc}
\hline \hline Indicated power (isothermal analysis) & $26.9 \mathrm{~W}$ \\
Gas hysteresis loss $^{\mathrm{a}}$ & $-10.5 \mathrm{~W}$ \\
Expansion space enthalpy loss & $-0.5 \mathrm{~W}$ \\
Cycle output work & $15.9 \mathrm{~W}$ \\
Bearing friction and eddy loss & $-1.4 \mathrm{~W}$ \\
Coil resistive loss & \\
Power delivered to electric load & $-5.2 \mathrm{~W}$ \\
\hline \hline
\end{tabular}

${ }^{\mathrm{a}}$ Indicates a directly measured parameter. All other parameters are calculated based on energy-balance principle and the measured values.
A summary of the above discussion is tabulated in Table 3. The isothermal Stirling engine model predicts $26.9 \mathrm{~W}$ mechanical output work. However, the recorded $p-V$ loop (Fig. 13) indicates an output work of $15.9 \mathrm{~W}$. The compression test, on the other hand, revealed that $10.5 \mathrm{~W}$ is dissipated as gas spring hysteresis. Therefore, the power balance principle suggests only a $0.5 \mathrm{~W}$ difference, which is well within the measurement uncertainty, or it can be attributed to the enthalpy loss through the expansion space walls. On the electric side, $9.3 \mathrm{~W}$ is delivered to the load as electric power and $5.2 \mathrm{~W}$ is dissipated as copper loss in the windings. Hence, the remaining $1.4 \mathrm{~W}$ (including measurement uncertainties) is dissipated as linear ball bearing friction and eddy loss in the power piston body that is solid low-carbon steel.

5.5 Thermal Characterization. In a different set of experiments, the following three operating conditions are considered for thermal measurements, and in each case, the measurements are recorded after reaching thermal equilibrium.

A. Static operation. The displacer piston is not driven, and, hence, the power piston does not oscillate either.

B. Locked power piston. The displacer piston is driven at $3 \mathrm{~Hz}$ and full stroke, while the power piston is locked to suppress its oscillation.

C. Normal operation. The displacer piston is driven at $3 \mathrm{~Hz}$ and full stroke, while the power piston is unlocked and connected to the electric resistive load.

A summary of the measurements for each case is tabulated in Table 4. In Experiment A, the electric power drawn from the power supply is equal to the sum of the thermal power leaking from the hot side of the engine to its cold side and the thermal power that is dissipated to the surroundings before reaching the heater. The latter is not negligible because sections of the electric heating element are exposed to the air, as seen in Fig. 11. The thermal leakage is mainly due to heat conduction through the heat

Table 4 Summary of the thermal experiments

\begin{tabular}{lcccccr}
\hline \hline Experiment & $\begin{array}{c}T_{h}^{\text {air }} \\
\left({ }^{\circ} \mathrm{C}\right)\end{array}$ & $\begin{array}{c}T_{k}^{\text {air }} \\
\left({ }^{\circ} \mathrm{C}\right)\end{array}$ & $\begin{array}{c}T_{\text {in }}^{\text {coolant }} \\
\left({ }^{\circ} \mathrm{C}\right)\end{array}$ & $\begin{array}{c}T_{\text {out }}^{\text {coolant }} \\
\left({ }^{\circ} \mathrm{C}\right)\end{array}$ & $\begin{array}{c}P_{e}^{\text {in }} \\
(\mathrm{W})\end{array}$ & $\begin{array}{c}\dot{Q}_{k} \\
(\mathrm{~W})\end{array}$ \\
\hline A. Static operation & 184 & 24.7 & 7.4 & 12.9 & 231 & 146 \\
B. Locked power piston & 184 & 27.0 & 6.0 & 14.5 & 335 & 187 \\
C. Normal operation & 184 & 25.9 & 6.6 & 14.9 & 417 & 215 \\
\hline \hline
\end{tabular}




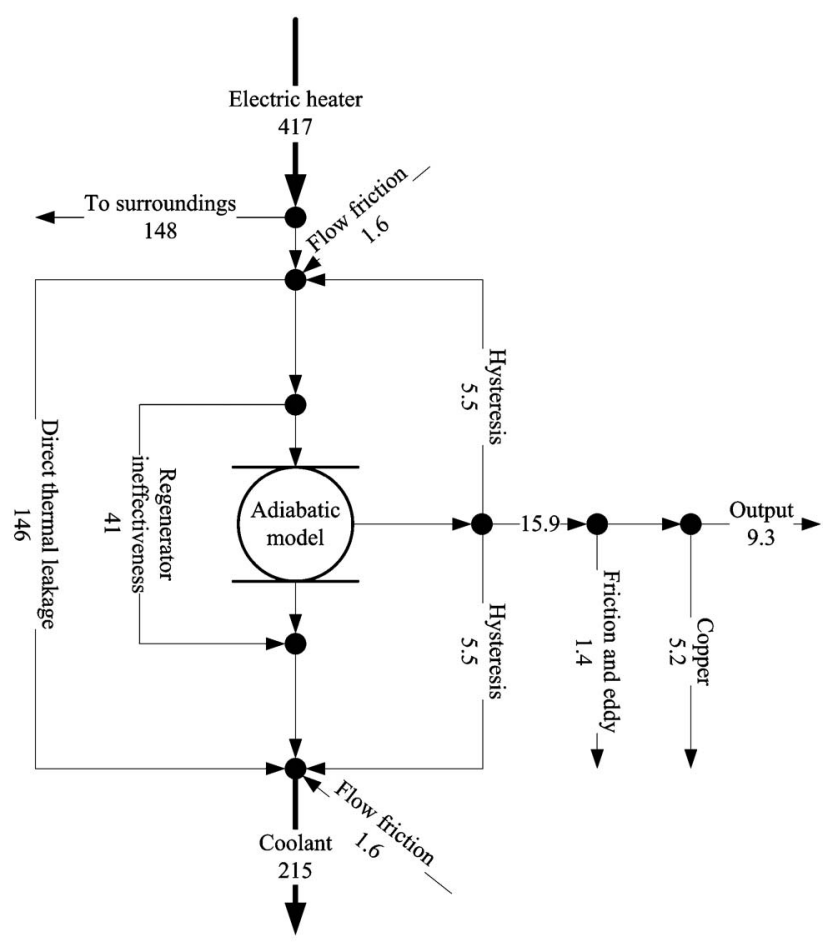

Fig. 14 Power balance diagram of the fabricated prototype. All the measured powers (in W) are noted on the diagram.

exchanger housing material (Teflon). The rejected heat at the cooler, estimated based on calorimetric principles, indicates this leakage, which, in this case, is $146 \mathrm{~W}$. Once the displacer piston is driven in Experiment B, one expects the thermal leakage to increase due to the ineffectiveness of the regenerator. Therefore, the difference between the rejected heat at the cooler in Experiments $\mathrm{A}$ and $\mathrm{B}$ (i.e., $41 \mathrm{~W}$ ) is equivalent to the heat leakage through the regenerator. Furthermore, in Experiment B, we expect the heat dissipation to the surroundings to increase due to exposing hotter air to more cylinder wall areas between the hot end of the displacer piston and the heater. The dissipation to the surroundings in Experiment B is $148 \mathrm{~W}$. Given the high-temperature difference (about $160^{\circ} \mathrm{C}$ ) across the thin cylinder wall (0.125 in.) and considering that the displacer cylinder is not thermally isolated in these three thermal experiments, $63 \mathrm{~W}$ of thermal leakage through the cylinder wall is feasible.

In Experiment B, the average coolant temperature is about $10^{\circ} \mathrm{C}$. In addition, due to the limited wetted area provided by the copper tubes, a temperature difference of about $14^{\circ} \mathrm{C}$ is required to transfer $187 \mathrm{~W}$ from the cooler tubes to the liquid coolant, which means that the temperature of the cooler fins and tubes is about $24^{\circ} \mathrm{C}$. The temperature of the working fluid (air) is measured at $27^{\circ} \mathrm{C}$ by the thermocouple that is placed inside the engine, very close to the cooler. Therefore, if the remaining temperature drop is attributed to the temperature difference between the working fluid and the heat exchanger interface, there is about $3{ }^{\circ} \mathrm{C}$ temperature rise from the copper tubes to the working fluid. This figure is close to the design calculations that were discussed in Sec. 4.2, which confirms the utilized methodology to estimate heat transfer characteristics of the cooler.

Experiment $\mathrm{C}$ is carried out to characterize thermal behavior of the engine at roughly the operating point discussed in Sec. 5.4. Input power from the electric supply is measured at $417 \mathrm{~W}$. Rejected heat is measured at $215 \mathrm{~W}$, as indicated in Table 4.

5.6 Efficiency. Figure 14 depicts the power balance diagram for the fabricated prototype engine, which is based on all the experimental assessments discussed so far. After subtracting input
Table 5 Parameters of a candidate high-power engine design

\begin{tabular}{|c|c|}
\hline Working fluid & Air \\
\hline Temperatures & $\begin{array}{c}T_{h}: 130^{\circ} \mathrm{C} \\
T_{k}: 27^{\circ} \mathrm{C}\end{array}$ \\
\hline Frequency & $10 \mathrm{~Hz}$ \\
\hline Pressure & 75 bars \\
\hline Indicated powers & $\begin{array}{l}\text { Adiabatic model } \\
\text { Input: } 15 \mathrm{~kW} \\
\text { Output: } 2.4 \mathrm{~kW}\end{array}$ \\
\hline Heater & $\begin{array}{l}\text { Open area: } 250 \mathrm{~cm}^{2} \\
\text { Length: } 1 \mathrm{~cm} \\
\text { Hydraulic diameter: } 0.1 \mathrm{~mm} \\
\text { Flow friction loss: } 4.32 \mathrm{~W} \\
\text { Temperature drop: } 0.5^{\circ} \mathrm{C}\end{array}$ \\
\hline Cooler & $\begin{array}{l}\text { Open area: } 250 \mathrm{~cm}^{2} \\
\text { Length: } 1 \mathrm{~cm} \\
\text { Hydraulic diameter: } 0.1 \mathrm{~mm} \\
\text { Flow friction loss: } 4.32 \mathrm{~W} \\
\text { Temperature drop: } 0.5^{\circ} \mathrm{C}\end{array}$ \\
\hline Regenerator & $\begin{array}{c}\text { Open area: } 600 \mathrm{~cm}^{2} \\
\text { Length: } 1 \mathrm{~cm} \\
\text { Hydraulic diameter: } 70 \mu \mathrm{m} \\
\text { Flow friction loss: } 11.72 \mathrm{~W} \\
\text { Effectiveness: } 98 \%\end{array}$ \\
\hline Displacer piston & $\begin{array}{c}\text { Diameter: } 12.7 \mathrm{~cm} \\
\text { Stroke: } 4 \mathrm{~cm}\end{array}$ \\
\hline Power piston & $\begin{array}{l}\text { Diameter: } 15 \mathrm{~cm} \\
\text { Stroke: } 4 \mathrm{~cm}\end{array}$ \\
\hline Gas spring hysteresis loss & $33 \mathrm{~W}$ \\
\hline
\end{tabular}

heat loss to the surroundings and also conductive heat loss through the machine (regenerator) housing, this diagram shows a $20.7 \%$ cycle efficiency, about $50 \%$ of the corresponding Carnot efficiency, which is $41.1 \%$. It further helps to identify the improvements that need to be considered in subsequent designs, namely, reduction in gas hysteresis dissipation, reduction in direct heat leakage through the engine body, increase in regenerator effectiveness, and elimination of the heat loss to the surroundings.

\section{High-Power Engine Design}

This paper provides a strong basis for the design of a higherpower Stirling engine that could be applied in commercial utilization in the proposed solar-thermal-electric system. The goal is to design a Stirling engine with $2-3 \mathrm{~kW}$ output power. It is desired to keep the operating frequency below an audible range. In addition, it is desired to keep the flow friction dissipation below $25 \mathrm{~W}$ as that is the main loading for the displacer piston and, hence, for its actuator. The flow friction losses are strongly dependent on the flow speed, which is partly dictated by the frequency of operation. Therefore, $10 \mathrm{~Hz}$ appears to be an appropriate choice of operating frequency.

The output power of the engine is, to first order, proportional to the displacer swept volume. To keep the cost low, it is proposed to use flexures to provide the bearing function for the displacer mass-spring subsystem rather than a linear motion ball bearing. Flexures are simple and very easy to manufacture. However, it appears to be a challenge to design a flexure for large piston excursions. Hence, the displacer piston excursion and diameter are chosen to be $2 \mathrm{~cm}$ and $13 \mathrm{~cm}$, respectively. Based on these dimensions, the mean pressure of the working fluid needs to be about 75 
bars to produce $2.5 \mathrm{~kW}$ of mechanical work. Table 5 tabulates the dimensions of a possible design and the corresponding calculated nonideal effects of the engine components. This design is projected to achieve a thermal efficiency of $16 \%$, which is about $65 \%$ of the Carnot efficiency at $27^{\circ} \mathrm{C}$ and $130^{\circ} \mathrm{C}$ temperatures. As expected from the foregoing theoretical models and experimental efforts, the dissipative effects of the engine are a small fraction of its output power (2.2\% in this design).

\section{Conclusion}

A promising case was outlined for the use of distributed solarthermal-electric generation based on low-temperature differential Stirling engine technology in conjunction with state-of-the-art solar-thermal collectors. Although the predicted efficiencies are modest, the estimated cost in \$/W for large scale manufacturing of these systems is quite attractive in relation to conventional photovoltaic technology.

Considering that the Stirling engine is the most challenging component in the proposed energy conversion system, the design, fabrication, and measurement results of a low-power free-piston Stirling engine prototype are presented in this paper. A very low loss resonant displacer piston was designed for the system using a magnetic spring. The power piston, which was not mechanically linked to the displacer piston, formed a mass-spring resonating subsystem with the gas spring, and had a resonant frequency matched to that of the displacer.

The design of heat exchangers was discussed, with an emphasis on their low fluid friction losses. The total power loss of the displacer piston, heat exchangers, and tubing at nominal conditions was measured at about $3.2 \mathrm{~W}$, which was well within the calculated range at the design stage. The fabricated engine prototype was successfully tested, and the experimental results are presented and discussed. Extensive experimentation on individual component subsystems confirmed the theoretical models and design considerations.

Experimental results were utilized to successfully identify the key components and the major causes of irreversibility and to verify the corresponding theoretical models. Based on the devel- oped models, a higher-power Stirling engine design was proposed to be an appropriate match for the solar-thermal collectors discussed in this paper.

\section{Acknowledgment}

The authors would like to extend their gratitude to the National Science Foundation for the financial support of the research presented in this paper (Award No. ECS-0424462). Also, they would like to thank Ben Lake and Joseph Gavazza of the Engineering Research Support Organization (ERSO) Machine Shop for their tremendous help in the design and fabrication of the prototype.

\section{References}

[1] Welford, W. T., and Winston, R., 1989, High Collection Nonimaging Optics, Academic, San Diego, CA.

[2] Apricus Solar Co. Ltd., Apricus Technical FAQ Series.

[3] SCHOTT-Rohrglas GmbH, SCHOTT Evacuated Tube Collector ETC 16

[4] Senft, J. R., 2002, An Introduction to Low Temperature Differential Stirling Engines, 5th ed., Moriya, River Falls, WI.

[5] Der Minassians, A., Aschenbach, K. H., and Sanders, S. R., 2004 "Low-Cost Distributed Solar-Thermal-Electric Power Generation," Proc. SPIE, 5185, pp. 89-98.

[6] "Solarbuzz" Solar Market Research and Analysis (www.solarbuzz.com), part of The NPD Group, Data retrieved in February 2011.

[7] Winston, R., 2007, "Solar Energy for Heat, Light, and Power," CITRIC Research Exchange Seminar, UC Berkeley.

[8] Der Minassians, A., 2007, "Stirling Engines for Low-Temperature SolarThermal-Electric Power Generation," Ph.D. thesis, EECS Department, University of California, Berkeley, Berkeley, CA.

[9] Der Minassians, A., and Sanders, S. R., 2007, "Multiphase Free-Piston Stirling Engine for Solar-Thermal-Electric Power Generation Applications," Fifth International Energy Conversion Engineering Conference, IECEC.

[10] Der Minassians, A., and Sanders, S. R., 2008, "Multiphase Stirling Engines," Sixth International Energy Conversion Engineering Conference, IECEC

[11] Der Minassians, A., and Sanders, S. R., 2007, "A Magnetically-Actuated Resonant-Displacer Free-Piston Stirling Machine," Fifth International Energy Conversion Engineering Conference, IECEC.

[12] Der Minassians, A., and Sanders, S. R., 2009, "Multiphase Stirling Engines," ASME J. Sol. Energy Eng., 131, p. 021013.

[13] Urieli, I., and Berchowitz, D. M., 1984, Stirling Cycle Engine Analysis, Hilger, Bristol.

[14] Kakac, S., and Liu, H., 2002, Heat Exchangers, Selection, Rating, and Thermal Design, 2nd ed., CRC, Boca Raton, FL.

[15] Thomas, B., and Pittman, D., 2000, "Update on the Evaluation of Different Correlations for the Flow Friction Factor and Heat Transfer of Stirling Engine Regenerators," Proceedings of the 35th Intersociety Engineering Conference on Energy Conversion, Vol. 1, pp. 76-84. 